\title{
"Effectiveness of Planned School Health Awareness Programme about Healthy Lifestyle on knowledge and practice of Adolescents"
}

\author{
Ms. Sandeep $\operatorname{Kaur}^{1}$, Mr. Dipti Y. Sorte ${ }^{2}$, Ms. Mugdha Sharma ${ }^{3}$ \\ ${ }^{\prime}$ (Nursing Tutor, Sidhu School of Nursing, India) \\ ${ }^{2}$ (Associate Professor, Himalayan College of Nursing) \\ ${ }_{3}^{3}$ (Assistant Professor Himalayan College of Nursing)
}

\begin{abstract}
The lifestyle of the Adolescents is a major issue in the today's society and it differs though nature \& experience of individual, so here is the study was conducted to assess the effectiveness of planned school health awareness programme on the knowledge and practice of adolescents about healthy lifestyle in selected school of Dehradun. A quantitative research with quasi-experimental approach \& one group pre-test post-test design was adopted. Convenient sampling technique was used. Fifty subjects were included in the study. The analysis of pre-test and post-test knowledge and practice score using paired t-test revealed that there was significant improvement. The mean of the post-test knowledge and practice score (11.72 \pm 3.26$)$ and $(27.38 \pm 3.48)$ was found to be higher than the mean of the pre-test knowledge and practice score $(7.06 \pm 2.17)$ and $(23.7 \pm 3.95)$. There was association between found in pre-test and post-test knowledge and practice score. The study concluded that the planned school health awareness programme resulted in significant improvement of knowledge and practice about healthy lifestyle among adolescents which was very helpful healthy individuals and their family, thus society in future.
\end{abstract}

Keywords: Adolescents, Healthy Lifestyle, Knowledge and Practice

\section{Introduction}

There is mainly eight stages human life like infancy, toddler, preschool, school age, early adolescence and late adolescence. Each stage plays an important role for the growth and development of individual in the areas of physical, psychosocial, psychosexual, intellectual and moral development ${ }^{1}$

Adolescence, is the second decade of life, is a period in which an individual undergoes major physical and psychological changes. It presents a window of opportunity to set the stage for healthy and productive adulthood and to reduce the likelihood of problems in the years that lie ahead. At the same time, it is a period of risk: a period when health problems that have serious immediate consequences can occur or when behavior problems that could have serious adverse effects on health in the future are initiated. ${ }^{2}$

According to Indian censes data more than 50\% population area covered by adolescents. Adolescent Health is the optimal state of wellbeing in all areas of life-physical, emotional, cognitive, social and spiritual. By using the broad definition of health adolescents are healthy when they engage in healthy behavior that contribute to a healthy lifestyle, they have the capacity to thrive in spite of stressors in life and they successfully engage in the developmental tasks of adolescence; and experience a sense of wholeness and well-being. ${ }^{3}$

\section{Objective}

2.1. To assess the effectiveness of school health awareness programme on the knowledge of adolescents about healthy lifestyle in selected school of Dehradun.

2.2. To assess the effectiveness of school health awareness programme on practice of adolescents about healthy life style in selected school of Dehradun.

2.3. To find out correlation between knowledge and practice scores of adolescents about healthy lifestyle with their selected demographic variables.

2.4. To find out the association between the pre-test mean score of adolescents' knowledge about healthy lifestyle with their selected demographic variables.

2.5. To find out the association between the pre-test mean score of adolescents practice about healthy lifestyle with their selected demographic variables. 


\section{Hypotheses}

All hypotheses were tested at 0.05 level of significance

3.1. $\quad \mathbf{H}_{1}$ : The mean post-test knowledge score of adolescents, who have received the planned school health awareness programme about healthy lifestyle, would be significantly higher than their mean pretest knowledge score.

3.2. $\quad \mathbf{H}_{2}$ : The mean post-test practice score of adolescents, who have received the planned school health awareness programme about healthy lifestyle regarding healthy lifestyle, would be significantly higher than their mean pretest practice score.

3.3. $\quad \mathbf{H}_{3}$ : There would be significant correlation between knowledge and practice score of adolescents about healthy lifestyle with their selected demographic variables.

3.4. $\quad \mathbf{H}_{4}$ : There would be significant association between the pre-test knowledge and practice score of adolescents about healthy lifestyle with their selected demographic variables.

\section{Review Of Literature:}

Following aspects of review of literature related to this study.

4.1. Literature related to healthy eating habits

4.2. Literature related to physical exercise / Activity and stress

4.3. Literature related to time management

4.4. Literature related to peer interaction

4.5. Literature related to reproductive health

4.6. Literature related to alcohol and tobacco use

5.1. Confined to specific small sample size

5.2. Practice was measured by self-reported not by direct observation

5.3. Adolescents might be sensitized by repeated exposure to the topic before evaluating by post-test

5.4. The researcher had no control over the event that took place between pre-test and post-test.

\section{Variables:}

Independent Variables: Planned School Health Awareness Programme

Dependent Variables: Knowledge and practice of adolescents regarding Healthy Lifestyle

Background Variables: Age, Gender, Residential area, Number of family members, Education status of parents, income, occupation of parents, informational media.

Conceptual framework: Modified "Health Belief Model" that was developed by Strecher.V.J. And Rosenstcok. I.M . (1997) model was used for present study. ${ }^{4}$

Research Approach:

\section{Research Methodology}

It adopted a quantitative experimental research approach.

Research Design:

It adopted a planned Quasi experimental one group pre-test post-test design.

Sample and Sampling Technique: The sample for the present study consists of school adolescents (12-19 years), in selected school of Govt. High Secondary school of Doiwala, Dehradun and convenient sampling technique were used.

Setting: The present study was conducted in the selected Govt. High Secondary school of Doiwala, Dehradun.

Inclusion criteria: The adolescents who were between age group of (12-19 years), who can speak, read and write Hindi and adolescents who were studying in selected school.

Data collection method: Self structured knowledge questionnaire for knowledge assessment and Self-reported Practice checklist was used to determine the practice of adolescents on healthy lifestyle.

Data collection procedure: The data collection was done in 2 stages

Pre-test stage data was collected through self-structured knowledge questionnaire and self-reported practice checklist. After pre-test conducted on selected sample, on the same day Planned School Health Awareness Programme was introduced.

Post-test stage post-test was conducted by using same knowledge questionnaire and self-reported practice checklist tool.

Validity and reliability: The reliability co-efficient of knowledge and practices calculated by spilt half method, test and retest method and by using spearman brown prophecy formula. Under descriptive statistics: Frequency, Percentage, Range of score, Mean, Standard Deviation and under inferential statistics - Paired' test was 
calculated to test the hypotheses independent $\mathrm{t}$ test was calculated to assess the significance between selected demographic variables and pre-test scores.

\section{Results:}

Findings related to demographic data: There was $62 \%$ students were below 16 years and $38 \%$ were above the age of 16 years of age. Maximum students $(60 \%)$ were $\leq 10^{\text {th }}$. Majority of students were $(54 \%)$ male. $84 \%$ students were belongs to rural area. Maximum students $(70 \%)$ were having family members' $\geq 4$. Majority of students $(78 \%)$ were belongs to Hindu religion. Most of student's father $(80 \%)$ was literate and $(60 \%)$ mothers were literate. About the number of elder siblings (50\%-50\%) students had $\leq 1$ and $\geq 2$ elder siblings in their family. Related to monthly income majority of students $(72 \%)$ had family monthly income $\leq 10,000$. Maximum student's father (94\%) was nonprofessional occupation. Majority of student's mother (82\%) were housewife. A large number of students (94\%) informed that they had information about healthy life habits. Only (58\%) students informed that source of information were parents and friends. The mean of the post-test knowledge score $(11.72 \pm 3.26)$ was found to be higher than the mean of the pre-test knowledge scores $(7.06 \pm 2.17)($ Table 1$)$ and for practice the mean of the post-test practice score $(27.38 \pm 3.48)$ was also found to be higher than the mean of the pre-test practice score $(23.7 \pm 3.95)$ (Table 2) Area wise post-test knowledge score of adolescents was found significantly higher than their mean pre-test knowledge score (Figure 1) Area wise post-test practice score of adolescents was found significantly higher than their mean pre-test practice score(Figure 2) Independent $t$ test significant at the level of $\mathrm{p}<0.05$ at $\mathrm{df}(48)$ tabulated $t$ value was 2.02 , there was no association between the pre-test knowledge score and selected variables such as age, class, gender, residential area, number of family member, religion, education status of father, education status of mother, number of elder siblings in the family, monthly income of family, occupation status of father, occupation status of mother, information about healthy habits, and source of information and there was no association between the pre-test practice score and selected variables such as age, class, residential area, number of family member, religion, education status of mother, number of elder siblings in the family, occupation status of father, occupation status of mother, monthly income of family, information about healthy habits, and source of information except gender and education status of the father, Hence the researcher failed to reject the null hypothesis at 0.05 level of Significance. There was linear correlation between gain in knowledge and gain in practice score of adolescents about healthy lifestyle. For each domain, as $t$ calculated value for each domain was more than t tabulated value for degree of freedom $49=2.02$ that was significant at the level of $\mathrm{p}<0.05$

\section{Conclusion}

Prior to the implementation of Planned School Health Awareness Programme, students had little knowledge about healthy lifestyle: its effectiveness was evaluated by post-test scores; The mean of the post-test knowledge score had improved from $(7.06 \pm 2.17)$ to $(11.72 \pm 3.26)$ was found to be higher than the mean of the pre-test knowledge scores and the mean of the post-test practice score had also improved from $(23.7 \pm 3.95)$ to $(27.38 \pm 3.48)$ after the implementation of Planned School Health Awareness Programme, which shows the effectiveness of awareness programme. An intervention The study was conducted by K. Malleshappa, et al.,( 2011) as Knowledge and attitude about reproductive health among rural adolescent girls in Kuppam mandal. ${ }^{5}$ They showed that the students' knowledge about puberty changes improved significantly after intervention $(\mathrm{P}<0.005)$. Students had a good knowledge regarding age at first menses and maintaining hygiene during menses at pre-test. The intervention significantly improved participants' knowledge $(\mathrm{P}<0.001)$. The awareness of students regarding different contraceptive methods. It was observed that their knowledge was poor during per-test and remarkable improvement was noted following intervention $(\mathrm{P}<0.0001)$.

\section{Nursing Implications}

\section{Nursing Practice:}

One of the activities in School Health Awareness Programme is to promote healthy lifestyle. The finding helps the school health nurse to improve her knowledge and practice about healthy lifestyle by school health awareness program thus it motivates the school adolescents to promote healthy lifestyle.

\section{Nursing Education:}

90\% students come under the adolescents group thus finding helps the teachers in guiding the students towards healthy lifestyle.

\section{Nursing Administration:}

The nurse administrator and teacher guide the students in conducting school health awareness programme on healthy lifestyle in different community affiliated organizations. 


\section{Nursing Research:}

The study helps to conduct the research for the nursing students to improve healthy lifestyle by preventing or controlling illness among students due to unhealthy lifestyle habits and promoting health of the adolescents by practicing healthy lifestyle habits.

\section{Recommendations:}

11.1. A comparative study regarding healthy lifestyle can be among the students of rural and urban area 11.2. A similar study can be replicated for specific healthy lifestyle habits among children

11.3. A comparative study can be conducted with different intervention programme regarding healthy lifestyle among school adolescents

\section{Reference}

[1]. Marlow Dorothy R, Redding Barbara A. text book of pediatric nursing: stages of human development. 6th edition. India: Elsevier private limited; 2010.174 .

[2]. Strengthening the health sector response to adolescent health and development [online].2009[ cited 2012 Dec 25]; Available from: URL: http://www.who.int/maternal_child adolescent/documents/cah_adh flyer_2010_12 en.pdf

[3]. Adolescents Transition: The Challenges And The Way Out (African Perspective)[online]. 2007[cited 2013 Jan 5]; [2-3]; Available from: URL: http://uaps2007.princeton.edu/papers/70720

[4]. Strecher.V.J. and Rosenstcok.I.M. "Health Belief Model".Jones and Bartlett. (1997) [cited 2013 June5]; Available from: URL: http://www.jblearning.com/samples/0763743836/chapter\%204.pdf

[5]. Malleshappa K, Shivaram Krishna, Nandini C. Knowledge and attitude about reproductive health among rural adolescent girls in Kuppam mandal: An intervention study. Indmedica [serial online] 2007 July [cited 2012 March 27] ; 22( 3). Available from:URL: http://www.indmedica.com/journals.php?journalid=12\&issueid=150\&articleid=2042\&action=article

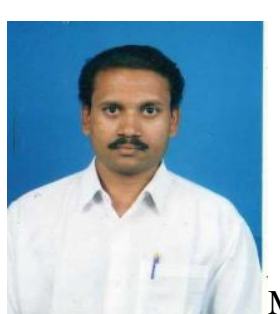

\section{About Author}

Mr. Dipti Y. Sorte working as Associate Professor in Himalayan College of Nursing at Swami Ram Himalayan University (S.R.H.U.) Dehradun 248140 since 2009. Mr. Dipti Sorte has Qualification of M Sc N Paediatrics, PBB Sc Nsg, GNM OR Tech, He has total 20 yrs. Of experience in Nursing Profession, out of that 10 yrs. purely in teaching, Currently he is a H.O.D. of Child Health Nursing Dept. also Lead Instructor for Regional Neonatal Resuscitation Programme associated with Dept. of Paediatrics Himalayan Institute of Medical Sciences \& Indian Academy of Paediatrics since 2010. He attended several National and state conferences and workshop, He at various level and designated from staff nurse to H.O.D. He guided more than 10 PG students as a Reader. 